samples from patients who failed to develop antibody, three were collected at $7 \frac{1}{2}-8$ weeks after vaccination and one at 6 weeks. It is possible that if these samples had been collected later antibody may have developed, so in the future it may be advisable to collect the postvaccination serum after a longer interval.

The results on 82 patients indicate that successful vaccination was higher in our group than in that described by Dr Roberts, but it would still appear to be worth while to examine samples collected at least 10 weeks after vaccination to confirm the presence of rubella antibodies, or the possible need for revaccination.

E D PEREIRA H N MACDONALD

St James's University Hospital, Leeds

M H HAMBLING

Public Health Laboratory, Leeds

\section{Infection with Epstein-Barr virus}

SIR,-There are two puzzling features in the report by Drs Hillas Smith and A M Denman on a new manifestation of infection with Epstein-Barr (EB) virus (22 July, p 248).

Firstly, they say that the antibody titre to EB virus capsid antigen (indirect immunofluorescence) was $1 / 5$ on 4 March and rose to $1 / 20$ on 26 July and $1 / 40$ on 13 September. This was a remarkable delay in an antibody which normally rises so early as to be of little help in the diagnosis of infectious mononucleosis. Two sentences later they state that "EB virus IgG was $1 / 512$ on 9 March." The most commonly measured "EB virus IgG" is antibody to the virus capsid antigen, said to be $1 / 5$ five days earlier and $1 / 20$ three months later. Can the authors offer some clarification of these conflicting statements?

Secondly, they report that four weeks after admission the titre of complement-fixing antibody to cytomegalovirus was $1 / 1024$ and specific IgM antibody was $1 / 32$. These titres, which would normally be considered good evidence of recent infection, are dismissed as "an anamnestic response." How vigorously was cytomegalovirus sought by repeated culture of urine, throat, and cervical swabs ?

Their evidence for infection by EB virus is (a) a Paul-Bunnell-Davidson titre which they describe as "weakly positive," $(b)$ the presence of anti-i antibody, titre unstated, and $(c)$ their conflicting statements about EB antibodies.

Should not cytomegalovirus either alone, or with $\mathrm{EB}$ virus infection, also be considered in discussing the aetiology of this illness ?

DAVID A WARRELI J O'H TOBIN

Radcliffe Infirmary,

A H TOMLINSON

Oxford

\section{Intravascular coagulation in falciparum malaria}

SIR,-Professor J Vreeken and $\mathrm{Mr}$ Th $\mathrm{M}$ Cremer-Goote (19 August, p 533) studied nine patients with falciparum malaria and reported a fall in plasma fibrinogen together with thrombocytopenia. They concluded that diffuse/disseminated intravascular coagulation (DIC) was not present, and postulated the adsorption of fibrinogen to cell membranes or leakage from the microcirculation as alternative mechanisms for the hypofibrinogenaemia.

Inflammatory conditions, including malaria, give rise to an acute-phase rise in the concentration of plasma fibrinogen and other proteins. The activity of coagulation factors in falciparum malaria should therefore be compared not only with normal values obtained from healthy controls but also with reference values obtained from other patients undergoing a similar inflammatory response.

We recently completed a serial coagulation study of 37 patients admitted with bacterial, viral, or protozoal infection. ${ }^{1}$ Patients with vivax malaria, compared with healthy uninfected controls, showed statistically significant thrombocytopenia, hyperfibrinogenaemia, and raised factor VIII antigenic (VIIIR:Ag) and coagulant (VIII:C) activity. Patients with falciparum malaria, when compared with vivax malaria, showed a statistically significant reduction in fibrinogen and platelets, increase in the ratio of factor VIIIR:Ag to factor VIII :C, and a positive serial-dilution protamine sulphate test for fibrin monomer. There was also a reduction in antithrombin III and increase in fibrin degradation products.

We would recommend the above approach in future coagulation studies in malaria to distinguish the acute-phase protein effect. Patients with falciparum malaria show evidence of coagulation activation; in some patients this may be interpreted as DIC, although the term is now used so loosely as to lack precise biological meaning.

Department of Haematology,

Queen Elizabeth Hospital,

Birmingham

${ }^{1}$ Richardson, S G N, et al, British fournal of Haematology. In press.

\section{Treatment of narcotic poisoning}

SIR,-The most recent articles on this subject still recommend that patients severely poisoned by certain narcotic drugs should be treated by eliminative procedures. In the popula Treatment of Common Poisonings, ${ }^{1}$ which is widely used as a reference book by casualty officers, the authors repeatedly emphasise that most patients recover without using methods to eliminate the poison. They nevertheless state categorically that when the plasma salicylate concentration exceeds $500 \mathrm{mg} / \mathrm{l}$ intensive forced diuretic treatment must (my italics) be started, and they also advocate eliminative measures for severe lithium, meprobamate, chloral, primidone, barbitone, and phenobarbitone poisoning. Lawson ${ }^{2}$ again insists that most poisoned patients should not be given anything beyond supportive therapy, but he also states: "There is no doubt that there are instances when these measures of elimination are extremely valuable and may be lifesaving." Vale, ${ }^{3}$ dealing with paediatric poisoning, likewise says that eliminative measures have a small place, but lays down that if the plasma salicylate concentration exceeds 500 $\mathrm{mg} / \mathrm{l}$ forced alkaline diuresis should be instituted.

The only reason why eliminative measure are recommended is that some of the poison is thereby removed from the body. But this does not prove that the patient's life will be saved. In assessing the value of treatment for a condition which varies infinitely in severity and from which the vast majority of patients recover without treatment-and poisoning is a typical example of such a condition-the only means of reaching the truth is by a controlled trial on a very large scale. Indeed, this has become part of the conventional wisdom of medicine when drugs and operations are being assessed, but for reasons which are not clear to me a less critical approach has been taken towards eliminative treatment for poisoning. We would do well to remember that analeptic drugs were widely recommended by the experts 25 years ago in treating the poisoned, and a Lancet leading article commented: "A succession of case-reports illustrated how bemegride could aid the recovery of many seriously poisoned patients; and experienced clinicians believed that many of these patients would have died if bemegride had not been used." I pointed all this out in an article in the Lancet in $1973,{ }^{5}$ and no one disputed my views in the correspondence columns. I even wrote to one of the most eminent advocates of eliminative measures and urged him to reply to me in the Lancet, but he declined on the main ground that any comments would occupy several pages.

As eliminative treatment is without doubt hazardous and as there is no worthwhile evidence that it is beneficial, I urge that it should no longer be used (except perhaps by those taking part in a controlled trial). Failing this, I urge that those who advocate eliminative measures should at least point out that they are doing so solely for theoretical reasons.

JOHN W TODD

Farnham
Surrey

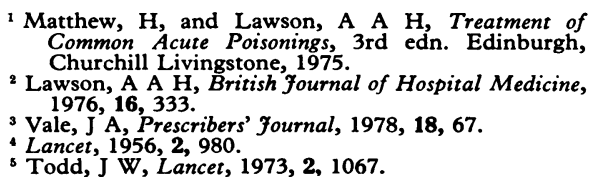

'Todd, J W, Lancet, 1973, 2, 1067.

\section{Secret list of MCQs}

SIR,-The value of employing repeatedly a secret list of multiple choice questions in various final medical examinations including the MRCP is now suspect.

Either a single copy of these questions may be smuggled out of the examination room despite the strict rules regarding such papers or students are asked to memorise two or three of the questions and give them to their teachers for future reference. By this means the secrecy is destroyed. The comments of students suggest that many of the questions are controversial and cover rare conditions. Surely there is no reason why the profession should not be allowed to see these questions, and if they are so limited in number the object of the examination is lost. Again, regarding the marking of papers, the mark-down for an error or guess seems irrationally severe.

Although marking the papers has been made easier, it is regrettably essential to reconsider the advisability of this type of examination. Although there are many books being produced displaying multiple choice questions and answers, the tendency does seem to invite abuse as well as rewarding some students who have a particular aptitude for this type of question? 